\title{
Triggers of Burnout among Tunisian Teachers at Higher Institutes of Sport and Physical Education
}

\author{
Nasr Chalghaf ${ }^{2}$, Fairouz Azaiez $^{1,2}$, Bechir Elarbi ${ }^{2}$ \\ ${ }^{1}$ High Institute of Sport and Physical Education of Sfax. Tunisia \\ ${ }^{2}$ Studies Group of Development and Social Environment (Faculty of Letters and Social Sciences of Sfax).Tunisia
}

\begin{abstract}
This study aimed to evaluate the effects of socio-professional triggers on the development of burnout syndrome among the institute's teachers of sports and physical education in Tunisia. The socio-professional triggers such as age, sex, teacher's grade, job seniority and the marital status of professors and the workplace to promote significantly the development of burnout syndrome among teachers at the institutes of sports and physical education in Tunisia. 269 teachers of the high institutes of sport and physical education male and female with mean ages (43, $21 \pm 7,704)$, answered the questionnaire of Maslach et al (1996). Our results of the regression analysis of the three components of burnout syndrome namely: emotional exhaustion, depersonalization and the loss of personal accomplishment are showed that the three models are significant at the same level of probability $(\operatorname{Pr} \leq 0.001)$. Also the $R^{2}$, which provide information on the share of contribution of predictors in the total variance components related, are respectively 0.67, 0.59 and 0.45 .
\end{abstract}

Keywords: Burnout, University Teachers, Physical Education

\section{Introduction}

Tunisia has known for more than a decade of profound changes at all levels, social, economic and cultural changes, revealing an unbalanced state structures and institutions. These changes are reflected also in the Tunisian university which must adapt to this situation, to continue to play its leading role such as the acquisition and transmission of knowledge, as well as new missions are dictated largely by scientific and technological developments that requires rehabilitation of the university. The difficulties affecting the teaching profession are many which include those inherent overstaffing students who are strong, quantitative and qualitative, the nature and frequency of requests from teachers in terms of psychological and physical resources; time pressure by reporting the amount of information processing that requires the teacher to work pending the weekends, which poses the problem of interference between work and professional life prevents the teacher to fill its full role in the family. While these tensions may affect his private life prevent him from relaxing at home, because it will keep in mind his professional concerns continue to spill over into his private life (Truchot, 2004).

Some organizational factors can be triggers of stress and tension for the teacher, which are on the one hand, the lack of autonomy and control over the allocation and scheduling tasks in the workplace, due to the centralization administrative and partitioning which results in the absence of the flow of information and the marginalization of the teacher in any event change Vézina (2001). On the other hand, the psychosocial factors related to labor relations as the lack of reports of consultation and coordination between them teachers in the management of educational and scientific activities, which raises the issue of social support. So for Desjours (2003) fun at work includes experience solidarity, friendliness and trust, it will be all the greater because the work is carried out in a truly collaborative work. The challenges and constraints experienced by the teacher in the absence of sources of satisfaction and adequate conditions for self-fulfillment may influence the onset of burnout .This syndrome is considered as the final stage of a break adaptation resulting from a long-term imbalance between the demands and work resources, and thus prolonged occupational stress and burnout (Cooper et al., 2004).

Burnout as it was defined by Freudenberger (1974) as "vacuum state" in which people respond to significant inquiries from their customers in the medical context (Truchot, 2009). Tunisia is a whole new culture so that no search is performed on this phenomenon. Study burnout syndrome is the question of occupational health differently, it is from an axis of psychosocial research focused our research topic.

The burnout antecedents are the elements predisposing syndrome, present in the organizational context or between workers interpersonal relationships. These can have a marked influence on the development of symptoms associated with burnout. Each individual carries a number of characteristics that influence mental health. In the study of burnout, the contribution of individual characteristics is often less important than the context-related characteristics in which the job runs (Maslach et al., 2001). In this section, a review of the literature specific to the individual variables will be advanced. More specifically, individual factors studied are gender, age, educational grade and marital status. 
The relationship between gender and burnout is not very strong. Some authors argue that the prevalence of burnout does not change according to gender (Ahola et al., 2006, 2007; Kowalski et al., 2010). Including among police officers (Burke et al., 2008; McCarty et al., 2009). However, studies show that burnout is higher among women than men (Estryn-Behar et al., 2010; Lindblom et al., 2006).

According to Truchot (2004), burnout does not necessarily increase with age and job seniority. However, Maslach (1982) reported that burnout appears after a year and a half among psychiatric nurses, between the second and the fourth year among social workers. According to Canoui (2001) there is a statistically significant relationship between age and the two dimensions of burnout, emotional exhaustion and dehumanization; also he noted that younger people are more vulnerable.

Some studies suggest a link between burnout and education grade. Schaufeli (2006), in his studies chowed that having a higher level of education could promote burnout. Also, Maslach et al. (2001) explains this relationship by the fact that a higher level of education is usually accompanied by greater responsibilities at work. Specifically, higher levels of education are generally associated with higher levels of cynicism and lower levels of professional efficacity (Maslach et al., 2001; Piko, 2006).

The literature shows that the professional relationship with, for example, nurses, practitioners and teachers are, by the nature of their employment, an increased risk of burnout (Taris, 2006). Burnout is a result of constant stress and is taking alarming proportions among university professors (Czernis, 2005). In fact, university teachers are now the professionals who demonstrate the highest levels of stress and burnout among social professions (Kinman, 2001; Leung et al, 2000; Taris et al., 2001; Winefield et al., 2003).

\section{Material and Methods}

This study was conducted in the current 2013/14 academic year and involved teachers in tunisian institutes of sport and physical education in Tunis, Sfax, Gafsa and kef, male and female, and their grades from teachers for secondary education to lecturers through assistants and lecturers. The average age is ranged from 30 to 58 years and their work experience ranged between 5 and 35 years. 269 teachers of the high institutes of sport and physical education male and female with mean ages $(43,21 \pm 7,704)$, answered the questionnaire of Maslach et al., (1996). The numbers of teachers were 107, 74, 34 and 54 respectively for the Institutes of Tunis, Sfax, Gafsa and Kef.

Although there are several instruments that can be used to measure burnout (Schaufeli \& Enzmann, 1998), the Maslach Burnout Inventory (MBI) is the most commonly administered measure (Maslach et al, 2001). The Third Edition MBI was used in this research as a measure of burnout consisting of 22 items measuring three factors (Maslach et al.,1996). Nine items measure emotional exhaustion, five items measure depersonalization, and eight items measure the loss of personal accomplishment. Maslach et al., (1996) has confirmed the construct validity of this measure with a diverse group of teaching professionals. Participants respond on a 7-point Likert Scale (Likert, 1932) with poles of never (0) and every day (6) measuring the frequency with which respondents experienced what was indicated in each statement. Previous reliabilities have been good, ranging from .71 to .90 (Maslach et al., 1996).

We present in this section the results of statistical analysis using SAS software to estimate the share of contribution of regressors in the explanation of the model. The syndrome of burnout has a physical and mental dimension whose components are emotional exhaustion, the depersonalization and the loss of personal accomplishment. This anomaly may be caused by various factors that may be personal to know the age, sex and marital status or directly related to his employment status such as grade and job seniority. We note that the dependent variable that is burnout is quantitative. However, the explanatory variables are qualitative, dichotomous and categorical. To do this, we conducted the regression analysis by the ANOVA procedure of the SAS library. This method can explain the contribution of the regressors in explaining the variance of the phenomenon of burnout. However, it does not specify the sign and magnitude of the influence of the independent variables. The multiple comparison test threshold probability of $95 \%$ was always used to separate the means.

\section{Results}

The results of the regression analysis of the three components of burnout syndrome namely: emotional exhaustion, depersonalization and the loss of personal accomplishment are shown in Table 1. They point out that the three models are significant at the same level of probability $(\operatorname{Pr} \leq 0.001) . \mathrm{R}^{2}$, which provide information on the share of contribution of predictors in the total variance components related, are respectively $0.67,0.59$ and 0.45 . The Table 1 also specifies the variances of each socio-professional history involved in the explanation of the patterns, the share of contribution to and the respective levels of significance. 
Tab.1-Variances and probability levels as sources of variation involved in the prediction of three-dimensional EE, DEP and PAP components of burnout syndrome among university teachers in higher institutes of sport and physical education in Tunisia.

\begin{tabular}{|c|c|c|c|c|c|}
\hline Variation Sources & Mean Square & PCVT (\%) & $\mathbf{F}$ & $\operatorname{Pr} \geq F$ & Ddl \\
\hline \multicolumn{6}{|c|}{$\begin{array}{r}\text { Emotional Exhaustion } \\
\left(\operatorname{Pr} \leq 0,001 ; R^{2}=0,67\right)\end{array}$} \\
\hline \multicolumn{6}{|l|}{ Triggers } \\
\hline Institute & 5337,39 & 30 & 73,35 & 0.0001 & 3 \\
\hline Sexe & 5998,46 & 11 & 82,44 & 0.0001 & 1 \\
\hline Age & 1053,68 & 10 & 14,48 & 0.0001 & 5 \\
\hline Grade & 2043,56 & 12 & 28,07 & 0.0001 & 3 \\
\hline Matrimonial State & 619,45 & 1 & 8,51 & 0,0039 & 1 \\
\hline Job Seniority & 164,09 & 2 & 2,26 & 0,031 & 7 \\
\hline Location & 432,47 & 1 & 5,97 & 0,015 & 1 \\
\hline \multicolumn{6}{|c|}{$\begin{array}{c}\text { Depersonalization } \\
\left(\operatorname{Pr} \leq 0,001 ; \mathrm{R}^{2}=0,59\right)\end{array}$} \\
\hline \multicolumn{6}{|l|}{ Triggers } \\
\hline Institute & 1158,9 & 25 & 50,92 & 0.0001 & 3 \\
\hline Sexe & 107,76 & 1 & 4,74 & 0.0305 & 1 \\
\hline Age & 343,67 & 13 & 15,1 & 0.0001 & 5 \\
\hline Grade & 709,52 & 16 & 31,18 & 0.0001 & 3 \\
\hline Matrimonial State & 174,66 & 1 & 7,68 & 0,006 & 1 \\
\hline Job Seniority & 67,22 & 3 & 2,95 & 0,005 & 7 \\
\hline Location & 52,25 & - & 2,3 & 0,131 & 1 \\
\hline
\end{tabular}

Loss of Personnel Accomplishment

$\left(\operatorname{Pr} \leq 0,001 ; R^{2}=0,45\right)$

\begin{tabular}{lccccc}
\hline Triggers & 824,22 & 7 & 10,36 & 0.0001 & 3 \\
Institute & 1366,91 & 4 & 17,17 & 0.0001 & 1 \\
Sexe & 1049,26 & 15 & 13,19 & 0.0001 & 5 \\
Age & 1661,49 & 13 & 2,89 & 0.0001 & 3 \\
Grade & 414,23 & 1 & 5,21 & 0,0233 & 1 \\
Matrimonial state & 172,76 & 3 & 2,17 & 0,0373 & 7 \\
Job Seniority & 589,64 & 1 & 7,41 & 0,0069 & 1 \\
Location & & & &
\end{tabular}

In general demographic variables studied are involved in the explanation of the components of burnout namely emotional exhaustion, the depersonalization and the loss of personal accomplishment (Table 1). However, their contributions are small and still remain variable as reflected by the values of the respective coefficients of determination ranged between 0.45 and 0.67 . Similarly, the share of participation of predictors for each dimension is different, mainly the variables as Workplace ',' Age 'and' Grade ',they best explain all models and therefore the syndrome of burnout among teachers of the Tunisian institutes of Sport and Physical Education (Table 1).

Overall all teachers in sport institutes of physical education in Tunisia are suffering from a high level of burnout (Table 2). Emotional exhaustion, the depersonalization and the loss of personal accomplishment are involved in the development of the latter even though the share of contribution of each one is variable. (Table 2).They also expressed the problem of loss of personal accomplishment but with variable degrees. The teachers at Kef institute who were least affected by the latter. Apart from the Institute of Kef, professing other institutions have shown severely degree of dehumanization. However, this is just at the Institute of Sfax and Tunis that the problem of emotional exhaustion was seriously found at teachers. Therefore, it seems that it is crucial in the excessive development of burnout syndrome. Indeed, where the level of emotional exhaustion is high burnout is also as it was noted in the institutes of Sfax and Tunis. 
Tab.2- Importance of the burnout syndrome affecting the teachers of the Tunisian higher institutes of sport and physical education according to the institute.

\begin{tabular}{|l|c|c|c|c|}
\hline \multirow{2}{*}{ Institutes } & \multicolumn{3}{|c|}{ *Dimensions } & \multirow{2}{*}{ *Burnout } \\
\cline { 2 - 5 } & Emotional Exhaustion & Depersonalization & Loss of Personnel Accomplishment & \\
\hline Sfax & $41 \mathbf{a}$ & $22 \mathrm{a}$ & $15 \mathrm{a}$ & High \\
\hline Tunis & $33 \mathbf{b}$ & $21 \mathrm{a}$ & $20 \mathbf{b}$ & High \\
\hline Gafsa & $30 \mathbf{c}$ & $17 \mathrm{~b}$ & $21 \mathbf{b}$ & High \\
\hline Kef & $19 \mathbf{d}$ & $12 \mathbf{c}$ & $24 \mathbf{b}$ & High \\
\hline
\end{tabular}

* The values in the same column followed by the same letter are not statistically different according to Duncan's multiple comparison test (Pr $\geq 0.05$ ).

Mostly, all the teachers of both sexes at the institutes of sport and physical education in Tunisia are highly suffering from burnout (Table 3). The dimensions of burnout such us emotional exhaustion, the depersonalization and the loss of personal accomplishment play an important role in the manifestation of burnout syndrome among male and female university professors at the institutes of sport and physical education in Tunisia. However, their shares of contribution to the development of the latter remain variable. Indeed, burnout among male professors in all institutes seems to be conditioned only by depersonalization dimensions and the loss of personal accomplishment. So in female teachers, it is determined by all components of the syndrome namely, emotional exhaustion, the depersonalization and the loss of personal accomplishment. Thus, it is the emotional exhaustion dimension that burnout is more important at institute's teachers of sport and physical education in Tunisia.

Tab.3-Importance of burnout syndrome affecting university teachers of higher institutes of sport and physical

\begin{tabular}{l|c|c|c|c|}
\multicolumn{4}{c}{ education in Tunisia all confused according to sex. } \\
Sexe & \multicolumn{3}{c}{ *Dimensions } & *Burnout \\
\cline { 2 - 4 } & Emotional Exhaustion & Depersonalization & Loss of Personnel Accomplishment & \\
\hline Female & $41 \mathbf{a}$ & $17 \mathrm{a}$ & $21 \mathrm{a}$ & High \\
\hline Male & $29 \mathbf{b}$ & $20 \mathrm{~b}$ & $16 \mathbf{b}$ & High \\
\hline
\end{tabular}

* The values in the same column followed by the same letter are not statistically different according to Duncan's multiple comparison test (Pr $\geq 0.05$ ).

In general, all teachers at the institutes of sport and physical education in Tunisia regardless their grade are highly suffering from burnout (Table 4).The emotional exhaustion, the depersonalization and the loss of personal accomplishment. Dimension, are heavily involved in the development of burnout syndrome among teachers of institutes of sport and physical education in Tunisia. However, the assistant and conferences masters who most suffer of these syndrome. In contrast, the professors of secondary education (PSE) have no problem of emotional exhaustion.

Tab.4-Importance of the burnout syndrome affecting university teachers at higher institutes of sport and physical education in Tunisia according to the grade.

\section{Grade}

\begin{tabular}{|c|c|c|c|c|}
\hline \multirow[t]{2}{*}{ Grade } & \multicolumn{3}{|c|}{ *Dimensions } & \multirow[t]{2}{*}{ *Burnout } \\
\hline & $\begin{array}{l}\text { Emotional } \\
\text { Exhaustion }\end{array}$ & Depersonalization & $\begin{array}{l}\text { Loss of Personnel } \\
\text { Accomplishment }\end{array}$ & \\
\hline P S E & $28 \mathbf{a}$ & $17 \mathrm{a}$ & $23 \mathbf{a}$ & High \\
\hline Assistant & $31 \mathbf{a}$ & $18 \mathbf{a}$ & $17 \mathbf{a b}$ & High \\
\hline Assistant Master & $40 \mathbf{b}$ & $24 \mathbf{b}$ & $14 \mathrm{bc}$ & High \\
\hline Conferences Master & $41 \mathbf{b}$ & $27 \mathbf{b}$ & $9 \mathrm{c}$ & High \\
\hline
\end{tabular}

Overall teachers at the institutes of sport and physical education in Tunisia with abstraction made in the age are too much suffering from burnout (Table 5). Overall dimensions, emotional exhaustion, depersonalization and the loss of personal accomplishment are involved in the induction of the phenomenon of burnout among university teachers from all higher institutes of sport and physical education in Tunisia apart according to age. However, éduquants whose age is between 30 and 35 years do not show problems of emotional exhaustion and probably why the burnout syndrome is not so pronounced at them compared to their older colleagues. 
Tab. 5 - Importance of burnout syndrome affecting university teachers of higher institutes of sport and physical education in Tunisia according to age.

\begin{tabular}{|l|c|c|c|c|}
\hline \multirow{2}{*}{ Age } & \multicolumn{3}{|c|}{ *Dimensions } & \multirow{2}{*}{ *Burnout } \\
\cline { 2 - 5 } & Emotional Exhaustion & Depersonalization & Loss of Personnel Accomplishment & \\
\hline $30-35$ & $24 \mathrm{a}$ & $14 \mathrm{a}$ & $26 \mathrm{a}$ & High \\
\hline $36-40$ & $30 \mathrm{~b}$ & $18 \mathrm{~b}$ & $22 \mathrm{~b}$ & High \\
\hline $41-45$ & $31 \mathrm{~b}$ & $19 \mathrm{~b}$ & $20 \mathrm{~b}$ & High \\
\hline $46-50$ & $32 \mathrm{~b}$ & $19 \mathrm{~b}$ & $20 \mathrm{~b}$ & High \\
\hline $51-55$ & $39 \mathrm{c}$ & $23 \mathrm{c}$ & $13 \mathrm{c}$ & High \\
\hline $56-60$ & $43 \mathrm{~d}$ & $25 \mathrm{c}$ & $10 \mathrm{c}$ & High \\
\hline * The values in the same column followed by the same letter are not statistically different according to Duncan's multiple comparison test (Pr $\geq 0.05)$.
\end{tabular}

Usually, all married and single teachers at the four institutes of sport and physical education in Tunisia are highly suffering from burnout (Table 4). The emotional exhaustion, depersonalization and the loss of personal accomplishment dimension are widely involved in the prevalence of burnout among singles university teachers among the four institutes. However, only the depersonalization and the loss of personal accomplishment participate in the development of the phenomenon among married teachers. Overall dimensions are all the problem of burnout is more pronounced in single teachers.

Tab. 6 -Importance of the burnout syndrome affecting university teachers of higher institutes of sport and physical education in Tunisia according to matrimonial state.

\begin{tabular}{|c|c|c|c|c|}
\hline \multirow[t]{2}{*}{ Matrimonial State } & \multicolumn{3}{|c|}{ *Dimensions } & \multirow[t]{2}{*}{ *Burnout } \\
\hline & Emotional Exhaustion & Depersonalization & Loss of Personnel Accomplishment & \\
\hline Single & $33 \mathbf{a}$ & $20 \mathbf{a}$ & $18 \mathbf{a}$ & High \\
\hline Married & $23 \mathbf{b}$ & $14 \mathbf{b}$ & $27 \mathbf{b}$ & High \\
\hline
\end{tabular}

Generally, all teachers at the institutes of sport and physical education in Tunisia are suffering from burnout and with a high way (Table 4).So the emotional exhaustion, the depersonalization and the loss of personal accomplishment dimension, all appear to be involved in the manifestation of burnout syndrome among university teachers from higher institutes of physical education in Tunisia and this regardless of the age (Table 7). Only teachers, whose career has not exceeded five years, do not show problems of emotional exhaustion.

Tab.7-Importance of the burnout syndrome affecting university teachers of higher institutes of sport and physical education in Tunisia according to the seniority.

\begin{tabular}{|l|c|c|c|c|}
\hline \multirow{2}{*}{ Seniority } & \multicolumn{3}{|c|}{ *Dimensions } & *Burnout \\
\cline { 2 - 5 } 1 à 5 years & Emotional Exhaustion & Depersonalization & Loss of Personnel Accomplishment & High \\
\hline 6 à 10 years & $20 a$ & $13 a$ & $28 a$ & High \\
\hline 11 à 15 years & $30 a b$ & $17 a b$ & $22 a b$ & High \\
\hline 16 à 20 years & $29 a b$ & $17 a b$ & $23 a b$ & High \\
\hline 21 à 25 years & $31 b c$ & $18 a b c$ & $20 a b$ & High \\
\hline 26 à 30 years & $35 b c d$ & $21 b c d$ & $15 b c$ & High \\
\hline 31 à 35 years & $40 c d$ & $23 c d$ & $14 b c$ & High \\
\hline
\end{tabular}

* The values in the same column followed by the same letter are not statistically different according to Duncan's multiple comparison test (Pr $\geq 0.05$ ).

\section{Discussion}

The burnout or burnout syndrome is a socio-professional anomaly that prevails more and more in the workplace. It expresses emotions of irritability, anger, inability to cope with stress and had a significant loss of energy (Truchot, 2004). Several factors such as socio-professional levels of sex, age, workplace, place of residence etc... may be the cause of the development of this syndrome among workers.

The objective of this study was to test the effects of certain socio-professional antecedents on the development of burnout syndrome among teachers of the institutes of sport and physical education in Tunisia.

Our study has shown that socio-professional antecedent such as age, sex, grade, job seniority, marital state of professors and the workplace to promote significantly the development of burnout syndrome among teachers of the institutes of Sport and physical Education in Tunisia. Indeed, the majority of teachers (100\%) 
seem to be suffering from this socio-professional anomaly. The manifestation of burnout is often goes with the outbreak of one built in individuals (Maslach et al., 1996).

Teaching is often considered as a job of help relationship with a high degree of stress. This can often be the cause of several problems that can undermine his psychological balance in his entourage. The study of Houlfort \& Sauvé (2010) clearly showed that burnout scores of teachers are significantly higher than those of other occupational groups such as health professionals, managers etc.

The Psychological disorders of teacher at the institutes of Sport and Physical Education of Tunisia appear to be largely dependent on socio-professional and organizational factors. Indeed, our study showed that burnout changes with age and job seniority of teachers of the institutes of sport and physical education in Tunisia. This corroborates with the latter observations of Canouï (2004) who reported that age is a factor of vulnerability through certain dimensions of burnout. It was always considered confused with age (Maslach et al., 2001). However, contrary to what is stated in our study, Truchot (2004) reported that in the scientific public, burnout does not necessarily increases with age and job seniority. Thus, Lambert et al. (2010) found that burnout was observed mainly in young employees early in their careers.

Our study also showed that burnout significantly affects teachers of the institutes of sport and physical education in Tunisia and that this phenomenon is more pronounced in the highest ranking mainly lecturers. This is consistent with the observations of Van den Broeck (2008) who reported a higher level of education could promote burnout. Maslach et al. (2001) explains this relationship by the fact that a higher level of education is usually accompanied by greater responsibilities at work. Higher the level of education, higher the degree of cynicism and is therefore more professional efficiency decreases (Piko, 2006).

Our results also showed that teachers of the institutes of Sport and Physical Education of Tunisia are more prone to the problem of burnout than their counterparts. Provided its nature, the woman was still considered much more emotionally vulnerable than man. This is consistent with the work of Estryn-Behar et al. (2007), Lindblom et al. (2006) who reported that burnout is often higher in women than in men. However, some authors argue that the prevalence of burnout does not change according to gender (Ahola et al, 2006, 2007; Kowalski et al., 2010). Including among police officers (Burke et al, 2006; McCarty et al, 2007). However, research supports that women have higher levels of emotional exhaustion (Maslach et al., 2001; Schaufeli and Enzmann, 1998) while men have higher levels of cynicism (Evans et al., 2006; Burke et al., 2006; McCarty et al., 2007.

Much more, and through our study, we show that the workplace contributes to the development of burnout syndrome among teachers of the institutes of sport and physical education in Tunisia. This is consistent with the work of McCormick et al., (2011), who reported that the type of school where teachers work, whether academic or otherwise, has its own sources of stress such as lack of equipment, administrative, organizational, etc...

Finally, our study showed that marital status is a factor that affects the appearance of the syndrome of burnout among teachers of the institutes of sport and physical education in Tunisia. Indeed, emotional stability could efficiently reduce the importance of this syndrome mainly at women (Pyhalto et al., 2011).

Indeed, married may be more or less protected from burnout despite the additional responsibilities they provide such as financial expenses, children's education and household chores (Skaalvik et al., 2011). This implies that the couple enjoys a balance between work and family life enjoying greater social support from their husbands (to), their families and friends, as opposed to singles. However, Van Houtte, (2011) showed an inverse relationship, whether married people have a higher level of burnout. Thus, singles are more vulnerable to stress.

\section{Conclusion}

Teachers' burnout has been recognized as a serious occupational problem in school systems worldwide (Loonstra et al., 2009). Several studies suggest that in comparison with other academic, client-related professions, teaching surpasses the average levels of stress, although there is significant contextual variation in teacher training and working conditions between countries (Akca \& Yaman, 2010). So burnout as a mental, emotional and physical shock snubs life professionals. It appears through our study among Tunisian high institute's teachers that teaching is so much stressful profession because of its high level of social interaction and the climate in which they occur. Indeed, our study showed that the socio-professional triggers such as age, sex, grade, job seniority, marital status and work place of teachers to influence significantly the development of burnout syndrome among teachers of the institutes of sport and physical education in Tunisia. Understanding burnout among teachers is particularly important, because the phenomenon has significant implications not only for teacher motivation, job satisfaction, health and longevity (seniority) (Jalongo \& Heider, 2006), but also for student behavior and learning (Dorman, 2003; meta-analysis by Montgomery \& Rupp, 2005). It has been shown that teacher burnout is related to an increased use of performance-oriented teaching practices (Retelsdorf et al., 2010), which are in turn related to increased cheating behavior (Anderman \& Midgley, 2004), more negative social relations (Tolmie et al., 2010) and less improvement in conceptual application skills among students 
(Gillies \& Ashman, 2003). Although the central role played by social interaction in teachers' occupational wellbeing has been known the complexity and dynamics of the social working environments provided by the school have often been neglected in studies on burnout among teachers (Devos et al., 2012; Parker et al., 2012).

\section{References}

[1]. Ahola, K., \& Hakanen, J. (2007). Job strain and depressive symptoms: A prospective study among dentists. Journal of Affective Disorders, 104, 103-110.

[2]. Ahola, K., Honkonen, T., Kivimaki, M., Virtanen, M., Isometsa, E., Aromaa, A., et al. (2006). Contribution of burnout to the association between job strain and depression: the Health 2000 study. Journal of Occupational and Environmental Medicine, 48, $1023-1030$.

[3]. Akca, F., \& Yaman, B. (2010). The effects of internal-external locus of control variables on burnout levels of teachers. Procedia Social and Behavioral Sciences, 2, 3976- 3980.

[4]. Anderman, E. M., \& Midgley, C. (2004). Changes in self-reported academic cheating across the transition from middle school to high school. Contemporary Educational Psychology, 29(4), 499-517.

[5]. Burke, R. J., Davis, R. A., \& Flett, G. L. (2008) Work aholism types, perfectionism and work outcomes. The Journal of Industrial Relations and Human Resources, 10, 30-40.

[6]. Canoui, P., \& Mauranges, A. (2004). Le burnout : le syndrome d'épuisement professionnel des soignants, de l'analyse aux réponses. Paris : Masson.

[7]. Canouï. P., mauranges. A. Le syndrome d'épuisement professionnel des soignants. De l'analyse du burnout aux réponses.. Ed. MASSON. Paris- 2de édition déc. 2001.

[8]. Cooper MD, Phillips RA. 2004. Exploratory analysis of the safety climate and safety behavior relationship. J Safety Res, 35:497512 .

[9]. Cooperative learning: The social and intellectual outcomes of learning in groups (pp. 1- 18). London: Routledge Falmer.

[10]. Czernis, L. (2005) L'affligeant problème du stress au travail chez les universitaires. Bulletin de l'Association Canadienne des Professeurs et Professeures Universitaires (ACPPU), 52(3), 3-5.

[11]. Dejours, C. 2003. L'évaluation du travail à l'épreuve du réel. Critique des fondements de l'évaluation, Paris, INRA Éditions.

[12]. Devos, C., Dupriez, V., \& Paquay, L. (2012). Does the social working environment predict beginning teachers' self-efficacy and feelings of depression? Teaching and Teacher Education, 28(2), 206- 217.

[13]. Dorman, J. P. (2003). Relationship between school and classroom environment and teacher burnout: a LISREL analysis. Social Psychology of Education, 6, 107-127.

[14]. Estryn-Béhar, M., Van der Heijden, B.I.J.M., Oginska, H., Camerino, D., Le Nezet, O., Conway, P.M., Fry, C., \& Hasselhorn, H.M. (2007). The impact of social work environment, Teamwork Characteristics, Burnout, and personal Factors upon Intent to Leave among European Nurses. Medical Care, 45, 939-950.

[15]. Evans, S., Huxley, P., Gately, C., Webber, M., Mears, A., Pajak, S., et al. (2006). Mental health, burnout, and job satisfaction among mental health social workers in England and Wales. The British Journal of Psychiatry, 188, 75-80.

[16]. Freudenberger, H. J. (1974). Staff burnout, Journal of Social Issues, 30(1), 159-165.

[17]. Gillies, R. M., \& Ashman, A. F. (2003). An historical review of the use of groups to promote socialization and learning. In R. M. Gillies, \& A. F. Ashman (Eds.), Jalongo, M. R., \& Heider, K. (2006). Teacher attrition: an issue of national concern. Early Childhood Education Journal, 33, 379- 380.

[18]. Houlfort, N., \& Sauvé, F. (2010). La santé psychologique des enseignants de la Fédération autonome de l'enseignement. Psychological health of teachers belonging to Federation autonome de l'enseignement. Montréal: École nationale d'administration publique.

[19]. Kinman, G. (2001) Pressure Points: A review of research on stressors and strains in UK academics. Educational Psychology, 21(4), 473-92.

[20]. Kowalski, C., Driller, E., Ernstmann, N., Alich, S., Karbach, U., Ommen, O. (2010). Associations between emotional exhaustion, social capital, workload, and latitude in decision-making among professionals working with people with disabilities. Research in Developmental Disabilities, 31(2), 470-479.

[21]. Lambert, E. G., Hogan, N. L., Jiang, S., Elechi, O., Benjamin, B., Morris, A., Laux, J. M., \& Dupuy, P. (2010). The Relationship Among distributive and Procedural justice and Correctional Life Satisfaction, Burnout, and turnover Intent: An Exploratory Study. Journal of Criminal Justice, 38(1), 7-16.

[22]. Leung, T.; Siu, O.; Spector, P.E. (2000) Faculty Stressors, Job Satisfaction, and Psychological Distress among University Teachers in Hong Kong: The Role of Locus of Control. International Journal of Stress Management, 7(2), 121-38.

[23]. Likert, R. (1932). A technique for the measurement of attitudes. Archives of Psychology, 140, 5-53.

[24]. Lindblom, K.M., Linton, S.J., Fedeli, C. \& Bryngelsson, I-L. (2006). Burnout in the working population: relations to psychosocial work factors. International Journal of Behavioral Medicine, 13, 51-59.

[25]. Loonstra, B., Brouwers, A., \& Tomic,W. (2009). Feelings of existential fulfillment and burnout among secondary school teachers. Teaching and Teacher Education, 25(5), 752-757.

[26]. Maslach, C. (1982). Understanding burnout: Definitional issues in analyzing a complex phenomenon. In W. S. Paine (Ed.), Job stress and burnout (pp. 29-40). Beverly Hills, CA: Sage.

[27]. Maslach, C., Schaufeli, W. B., \& Leiter, M. P. (2001). Job burnout. In S. T. Fiske, D. L. Schacter, \& C. Zahn-Waxler (Eds.), Annual Review of Psychology (Vol. 52, 397-422).

[28]. Maslach, C., Schaufeli, W. B., \& Leiter, M. P. (2001). Job burnout. Annual Review of Psychology (Vol. 52, 397-422).

[29]. Maslach, C.; Jackson, S.E.; Leiter, M.P. (1996) Maslach Burnout Inventory $3^{\text {rd }}$ Edition. California: Palo Alto. 52p.

[30]. McCarthy, C. J., Lambert, R. G., O'Donnell, M., \& Melendres, L. T. (2009). The relation of elementary teachers' experience, stress, and coping resources to burnout symptoms. Elementary School Journal, 109(3), 282-300.

[31]. McCormick, J., \& Barnett, K. (2011). Teachers' attributions for stress and their relationships with burnout. International Journal of Educational Management, 25(3), 278,293.

[32]. Montgomery, C., \& Rupp, A. A. (2005). A meta-analysis for exploring the diverse causes and effects of stress in teachers. Canadian Journal of Education, 28, 458-486.

[33]. Parker, P. D., Martin, A. J., Colmar, S., \& Liem, G. A. (2012). Teachers' workplace wellbeing: exploring a process model of goal orientation, coping behavior, engagement, and burnout. Teaching and Teacher Education, 28(4), 503- 513.

[34]. Piko, B.F., (2006). "Burnout, Role Conflict, Job Satisfaction and Psychosocial Health among Hungarian Health Care Staff: A Questionnaire Survey”, International Journal of Nursing Studies, Vol.43, pp.311-318. 
[35]. Pyhalto, K., Pietarinen, J., \& Salmela-Aro, K. (2011). Teacher and working-environment fit as a framework for burnout experienced by Finnish teachers. Teaching and Teacher Education, 27, 1101, 1110.

[36]. Retelsdorf, J., Butler, R., Streblow, L., \& Schiefele, U. (2010). Teachers' goal orientations for teaching: associations with instructional practices, interest in teaching, and burnout. Learning and Instruction, 20(1), 30-46.

[37]. Schaufeli, W.B. (2006), "The balance of give and take: toward a social exchange model of burnout", The International Review of Social Psychology, Vol. 19, pp. 87-131.

[38]. Skaalvik, E. M., \& Skaalvik, S. (2011). Teacher job satisfaction and motivation to leave the teaching profession: relations with school context, feeling of belonging, and emotional exhaustion. Teaching and Teacher Education, 27, $1029,1038$.

[39]. Taris, T. (2006). Is there a relationship between burnout and objective performance? A critical review of 16 studies. Work \& Stress, 20, 316-334.

[40]. Taris, T.W.; Schreurs, P.J.G.; Van Iersel-Van Silfhout, I.J. (2001) Job stress, job strain, and psychological withdrawal among Dutch universtiry staff: towards a dual-process model for the effects of occupational stress. Work et stress, 15(4), 283-96.

[41]. Tolmie, A. K., Topping, K. J., Christie, D., Donaldson, C., Howe, C., Jessiman, E., et al. (2010). Social effects of collaborative learning in primary schools. Learning and Instruction, 20(3), 177-191.

[42]. Truchot, D. (2004). Epuisement Professionnel et Burnout. Paris: Dunod.

[43]. Truchot, D. (2009). Le burnout des médecins généralistes : Influence de l'inéquité perçue et de l'orientation communautaire. Annales Medico-psychologiques, 167, 422-428.

[44]. Van den Broeck, A., Vansteenkiste, M., De Witte, H., \& Lens, W. (2008). Explaining the relationships between job characteristics, burnout, and engagement: the role of basic psychological need satisfaction. Work \& Stress, 22(3), $277,294$.

[45]. Van Houtte, M. (2011). So where the teacher in school is affects research? The impact of teachers' beliefs, culture and behavior on equity and excellence in education. In K. Van den Branden, P. Van Avermaet, \& M. Van Houtte (Eds.), Equity and excellence in education: Towards maximal learning opportunities for all students (pp. 75, 95).

[46]. Vézina, M. et Bourbonnais, R. (2001). Incapacité au travail pour des problèmes de santé mentale, ch.12, dans Portrait social du Québec - Données et analyses. Institut de la Statistique du Québec. Québec : Les conditions de vie.

[47]. Winefield, A.H.; Gillespie, N.; Stough, C.; Dua, J.; Hapuarachchi, J.; Boyd, C. (2003) Occupational Stress in Australian University Staff: Results From a National Survey. International Journal of Stress Management, 10 (1), 51-63. 